Article

\title{
Improving Water Leaving Reflectance Retrievals from ABI and AHI Data Acquired Over Case 2 Waters from Present Geostationary Weather Satellite Platforms
}

\author{
Bo-Cai Gao * and Rong-Rong Li \\ Remote Sensing Division, Code 7232, Naval Research Laboratory, Washington, DC 20375, USA; \\ rong-rong.li@nrl.navy.mil \\ * Correspondence: gao@nrl.navy.mil
}

Received: 2 September 2020; Accepted: 4 October 2020; Published: 7 October 2020

check for updates

\begin{abstract}
The current generation of geostationary weather satellite instruments, such as the Advanced Baseline Imagers (ABIs) on board the US NOAA GOES 16 and 17 satellites and the Advanced Himawari Imagers (AHIs) on board the Japanese Himawari-8/9 satellites, have six channels located in the visible to shortwave IR (SWIR) spectral range. These instruments can acquire images over both land and water surfaces at spatial resolutions between 0.5 and $2 \mathrm{~km}$ and with a repeating cycle between 5 and $30 \mathrm{~min}$ depending on the mode of operation. The imaging data from these instruments have clearly demonstrated the capability in detecting sediment movements over coastal waters and major chlorophyll blooms over deeper oceans. At present, no operational ocean color data products have been produced from $\mathrm{ABI}$ data. Ocean color data products have been operationally generated from $\mathrm{AHI}$ data at the Japan Space Agency, but the spatial coverage of the products over very turbid coastal waters are sometimes lacking. In this article, we describe atmospheric correction algorithms for retrieving water leaving reflectances from $\mathrm{ABI}$ and $\mathrm{AHI}$ data using spectrum-matching techniques. In order to estimate aerosol models and optical depths, we match simultaneously the satellite-measured top of atmosphere (TOA) reflectances on the pixel by pixel basis for three channels centered near 0.86 , 1.61 , and $2.25 \mu \mathrm{m}$ (or any combinations of two channels among the three channels) with theoretically simulated TOA reflectances. We demonstrate that water leaving reflectance retrievals can be made from ABI and AHI data with our algorithms over turbid case two waters. Our spectrum-matching algorithms, if implemented onto operational computing facilities, can be complimentary to present operational ocean versions of atmospheric correction algorithms that are mostly developed based on the SeaWiFS type of two-band ratio algorithm.
\end{abstract}

Keywords: remote sensing; sensors; ocean color; sediment; turbid water; chlorophyll; geostationary satellite

\section{Introduction}

The present geostationary weather satellite instruments, such as the Advanced Baseline Imagers (ABIs) on board the US GOES 16 and 17 satellites and the Advanced Himawari Imagers (AHIs) on board the Japanese Himawari-8/9 satellites, have six channels located in the visible to shortwave IR (SWIR) spectral range. These instruments can take images over land and water areas at spatial resolutions between 0.5 and $2 \mathrm{~km}$ and with a repeating cycle between 5 and 30 min depending on the mode of operation. The imaging data from these instruments and from other geostationary weather satellite instruments have clearly demonstrated the capability in detecting sediment movements over coastal waters and major chlorophyll blooms over deeper oceans [1-3].

During the early planning stage of GOES-R (now renamed as GOES-16), NASA, and NOAA envisioned the Hyperspectral Environment Suite (HES) instrument [4] to fulfill the future needs 
and requirements of the NESDIS (National Environmental Satellite, Data, and Information Service) Office [4]. NOAA was once very interested in the coastal waters (CW) task. HES was supposed to have an instrument like an imaging spectrometer to have hourly coverages over the US east coast, west coast, Gulf of Mexico, and Hawaii coastal waters. Later on, HES was canceled by the GOES-R Project because of cost constraints, while ABI remained on GOES-R. Due to the lack of a green band on ABI, NOAA has not generated operational ocean color data products, including suspended sediments, from ABI data. On the other hand, through visual inspection of GOES-R visible band images and movies provided on a web site at the Colorado State University (CIRA), it is easy to find interesting cases of ocean color observations with ABI. Figure 1 shows such an example. Figure 1A-D are false color images (Red: $0.64 \mu \mathrm{m}$; Green: $0.865 \mu \mathrm{m}$, Blue: $0.47 \mu \mathrm{m}$ ) acquired at UTC 1332, 1532, 1732, and 1932, respectively, on September 14, 2017 over the coastal areas of Florida. The silt stirred up by Hurricane Irma was captured in the Gulf Stream and advected northward while spinning off eddies. The original movie images at a time interval of five minutes can be found from http://rammb.cira.colostate.edu/ramsdis/online/loop_of_the_day/ for the day of 2017/09/14.
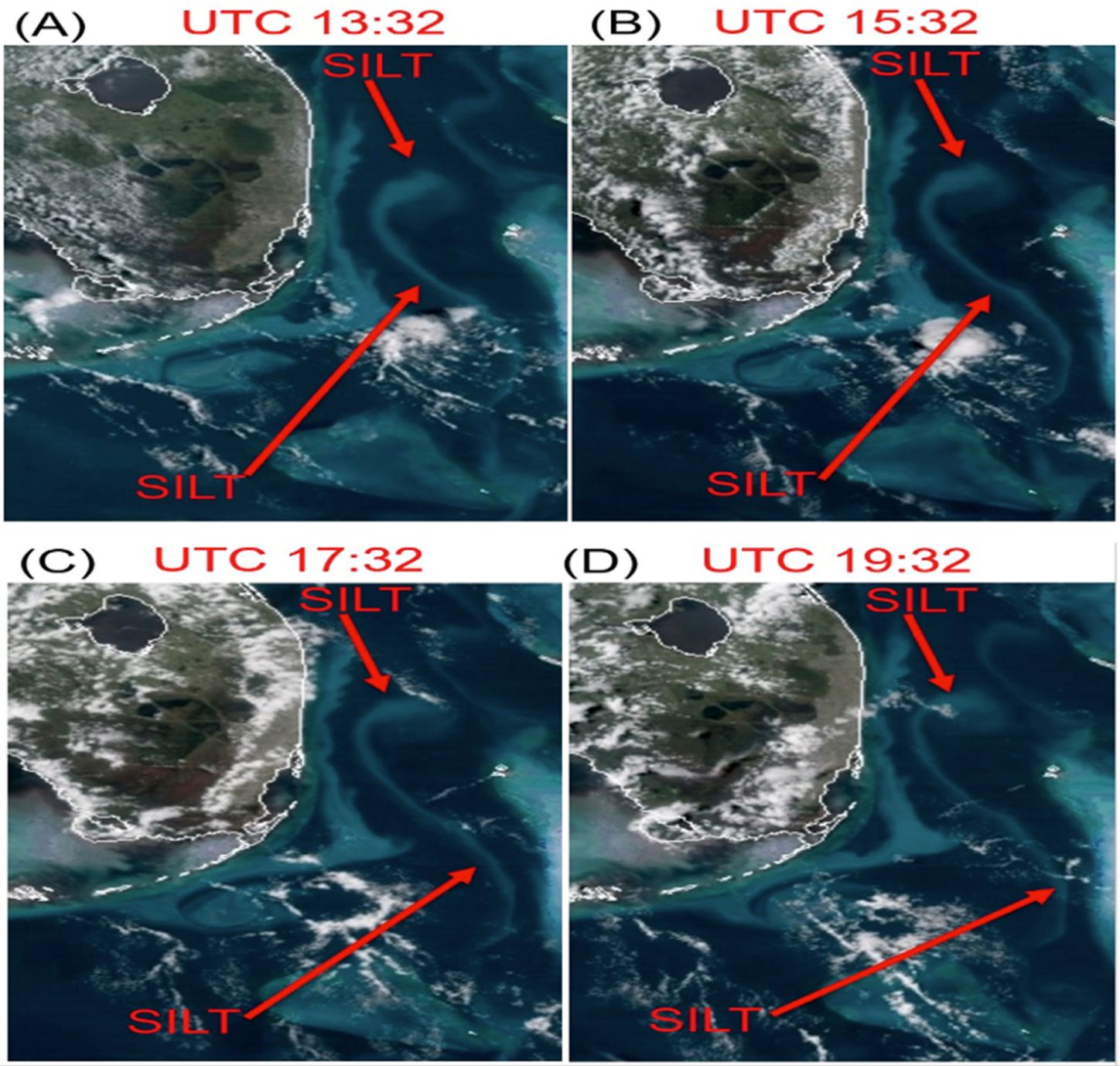

Figure 1. (A-D): time series of Advanced Baseline Imagers (ABI) images acquired at UTC 1332, 1532, 1732, and 1932 on September 14, 2017. The silt stirred up by Hurricane Irma was captured in the Gulf Stream and advected northward while spinning off eddies.

It should be pointed out that the silt features in Figure 1 are absent in images acquired under normal atmospheric wind conditions. With polar orbiting ocean color instruments, such as the aqua 
moderate resolution imaging spectroradiometer (MODIS) [5] and visible infrared imaging radiometer suite (VIIRS) [6], having a two-day global coverage, it was impossible to capture the rapid silt movement after the major hurricane event. Figure 1 also demonstrates partial coastal watch capabilities with ABI originally intended by NOAA using the HES instrument. At present, due to the lacking of a green channel on ABI, no operational ocean color data products have been produced from ABI data at NOAA. If operational ocean color data products were produced, our ability in monitoring water discharging from major US river systems to oceans and tracking turbid water movements over coastal waters could have been greatly improved because of rapid repeating cycles of ABI measurements.

The Japanese AHI instruments on board the Himawari-8/9 geostationary satellite platforms are equipped with a green band. Operational ocean color data products have been generated at the Japan Aerospace Exploration Agency (JAXA). The atmospheric correction algorithm for processing AHI data was described by Murakami [7]. This algorithm was adapted from an earlier version of the atmospheric correction algorithm [8] developed for processing the Japanese Global Imager (GLI) data, while the GLI algorithm shared the same basis with the SeaWiFS algorithm [9]. During the atmospheric correction processes using SeaWiFS-types of algorithms, the pure Rayleigh scattering effects for two bands are first subtracted out. The ratio of the two bands is then calculated. From the ratio value, an aerosol model for a given pixel is estimated. One problem with the ratio calculation for optical bands with additive noises is that it magnified the noise by a factor of 2 [10]. The noise is then propagated down to the derived water leaving reflectances of visible bands. In order to improve signal to noise ratios of measured AHI data, temporal averaging on the hourly basis is required for operational atmospheric corrections to AHI data [7]. Figure 2 shows sample ocean color results downloaded from a public Himawari web site (eroc.jaxa.jp/ptree/index.html). Figure 2a is an RGB image covering eastern part of China-Korea Peninsula, and part of Japan. The image was acquired on May 28, 2017 at UTC 0200. Land/water boundaries are drawing in yellow colored lines. Turbid coastal waters in eastern part of China and around the Korean Peninsula are seen obviously. Figure $2 b$ is the corresponding false color chlorophyll concentration image overlaid on the RGB image. Over portions of turbid coastal water areas, such as those areas pointed by arrows, no retrievals are made. Figure $2 \mathrm{c}$ is another case of false color chlorophyll concentration image overlaid on the RGB image. The AHI data was acquired on April 26, 2020 at UTC 0300. In this specific case, no retrievals were made over most water surfaces in eastern coastal areas of China.

Historically, the first geostationary ocean color sensor, the geostationary ocean color imager (GOCI) [11], was launched into space in 2010. This sensor has eight SeaWiFS-like bands. Several atmospheric correction algorithms [12-16] sharing the same base as the SeaWiFS 2-band ratio algorithm but with additional assumptions about absorption and scattering properties of coastal waters in the $0.66-0.865 \mu \mathrm{m}$ spectral range have been developed. The performance of these algorithms has been objectively evaluated [17]. The majority of multi-spectral and hyperspectral ocean versions of atmospheric correction algorithms have recently been reviewed in a lengthy paper by Frouin et al. [18]. Because GOCI lacks SWIR bands above $1 \mu \mathrm{m}$ for atmospheric correction purposes, the spatial coverage of atmosphere-corrected GOCI data products over very turbid coastal waters is also frequently lacking.

In view of the absence of $\mathrm{ABI}$ ocean versions of atmospheric correction algorithms and the needs for improving spatial coverage over turbid coastal water areas with AHI ocean color retrievals, we have recently developed spectrum-matching versions of atmospheric correction algorithms using SWIR bands above $1 \mu \mathrm{m}$, where the turbid coastal water surfaces are often very dark, for retrieving water leaving reflectances from $\mathrm{ABI}$ and $\mathrm{AHI}$ data. In Section 2 of this article, we describe the spectral characteristics of $\mathrm{ABI}$ and $\mathrm{AHI}$ instruments and the spectrum-matching technique for water leaving reflectance retrievals. We present sample retrievals from ABI and AHI data in Section 3. We give a short discussion in Section 4. Finally, we provide a brief summary in Section 5. 


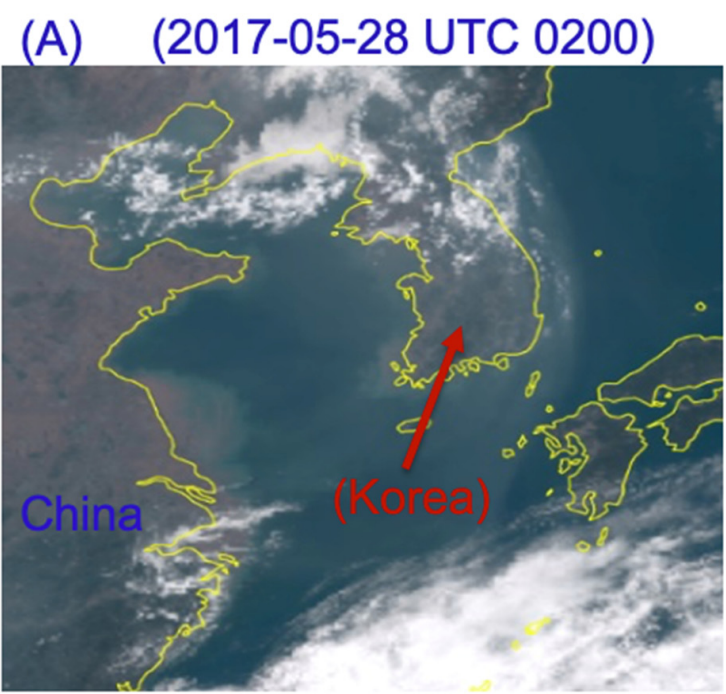

(B) (2017-05-28 UTC 0200)

(C) $(2020-04-26$ UTC 0300)

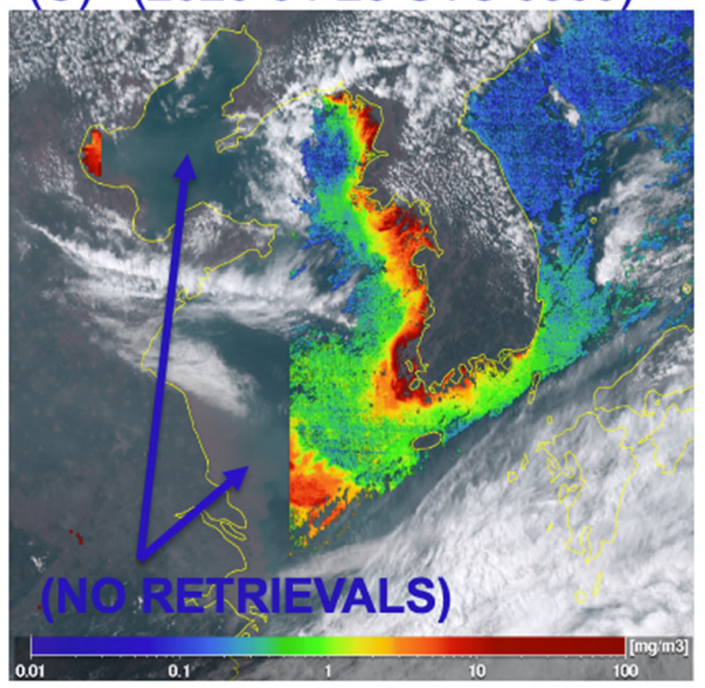

Figure 2. (A): A true color RGB image acquired with the Japanese Advanced Himawari Imagers (AHI) instrument over part of Japan, Korean Peninsula, and eastern part of China at UTC 0200 on May 28, 2017; (B): Similar to (A) but with a false chlorophyll concentration image overlaid; and (C): Another case of an AHI false color chlorophyll concentration image overlaid on an RGB image that was acquired on April 26, 2020 at UTC 0300.

\section{Data and Methods}

\subsection{The ABI and AHI Instrument Characteristics}

The ABI instruments, currently on board the NOAA GOES 16 and 17 geostationary weather satellite platforms, have six bands in the solar spectra range. These bands are centered near 0.47 , $0.64,0.865,1.378,1.61$, and $2.25 \mu \mathrm{m}$. The positions and widths of these bands are illustrated in Figure 3. The bands are plotted above a green algae reflectance spectrum, which was retrieved from an AVIRIS (airborne visible infrared imaging spectrometer) [19] data set acquired over a salt pond in the San Francisco Bay in August of 2009, with a version of our hyperspectral atmospheric correction algorithm (ATREM) [20]. It is obvious to see that ABI does not have a green band to center near the $0.55 \mu \mathrm{m}$. To improve the ocean color capability, the Japanese AHI instruments on board the Himawari-8/9 geostationary satellite platforms are equipped with a green band centered at $0.51 \mu \mathrm{m}$, which is illustrated in Figure 3. The basic designs of AHI are the same as those of ABI, except filter changes. AHI replaced ABI's $1.378-\mu \mathrm{m}$ cirrus band with the $0.51-\mu \mathrm{m}$ green band. The addition of the 
green band enhances the water color information that can be obtained from the AHI data in comparison with that from the ABI data.

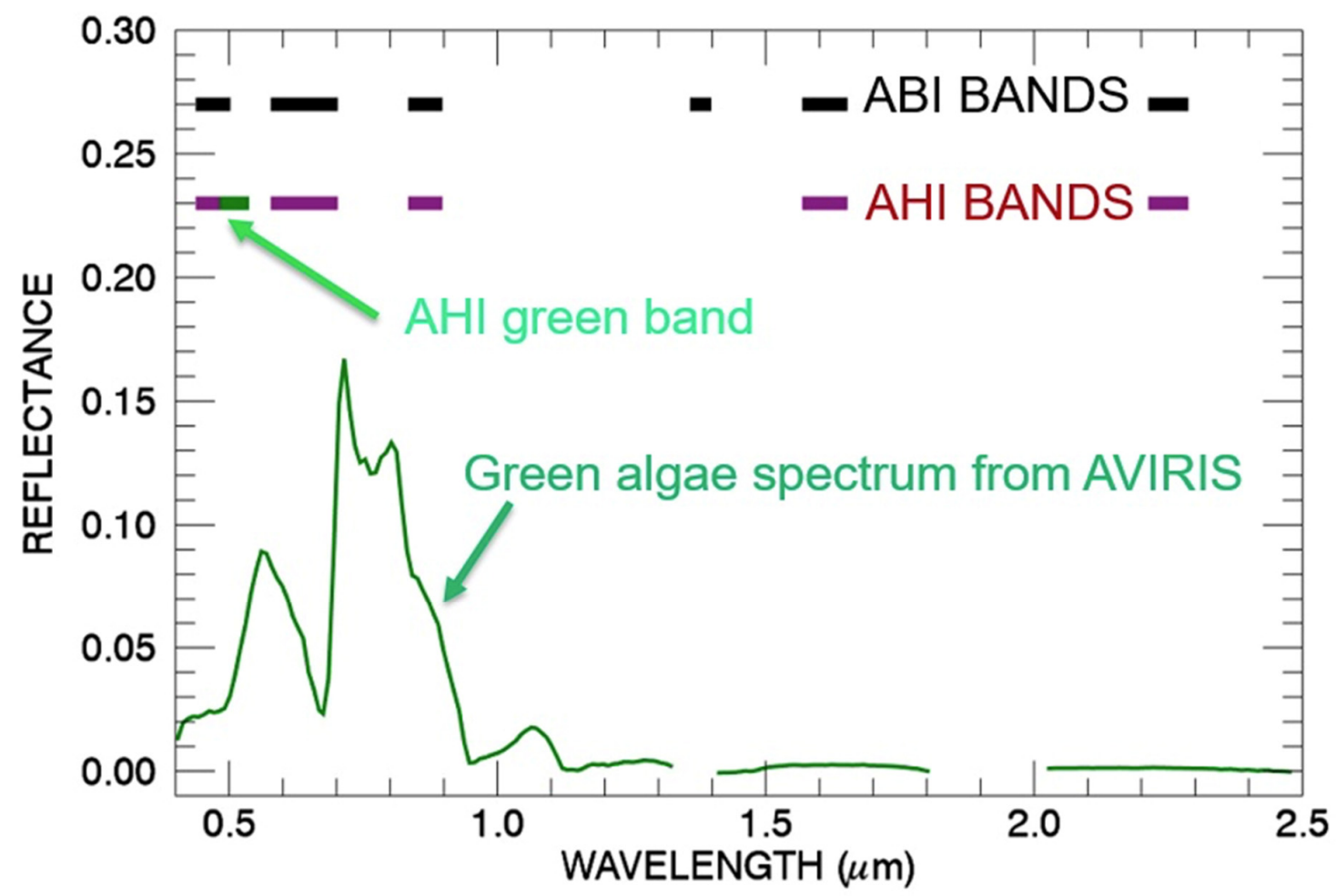

Figure 3. Bandpasses of ABI and AHI instruments. An airborne visible infrared imaging spectrometer (AVIRIS) green algae reflectance spectrum is also shown.

\subsection{Atmospheric Corrections for ABI and AHI Data}

At present, most ocean color data products have been generated from polar orbiting satellite data at various data centers. Atmospheric correction algorithms used for data product generations are mostly based on the Gordon and Wang [9] (hereafter referred as GW94) SeaWiFS types of 2-band algorithms that were designed mainly for clear deep ocean waters (case 1 waters). In the GW94 algorithm, the SeaWiFS $0.75-\mu \mathrm{m}$ and $0.86-\mu \mathrm{m}$ bands are used as atmospheric correction bands assuming water leaving reflectances from the two bands are close to zero. Over coastal waters, suspended sediments can contribute non-negligible water leaving reflectances to the $0.75-$ and $0.86-\mu \mathrm{m}$ bands. Several investigators have tried to remove the NIR water leaving reflectance contributions from the measured top-of-atmosphere NIR apparent reflectances with different techniques [21,22], so that a "black pixel" could be provided to the SeaWiFS 2-band ratio type of atmospheric correction algorithms.

Previously, we developed an ocean version of hyperspectral atmospheric correction algorithm [20] mainly for supporting the Navy COIS (coastal ocean imaging spectrometer) project [23]. For the turbid coastal environment, the water leaving radiances in the $0.75-0.865 \mu \mathrm{m}$ spectral range are typically not close to zero mainly because of scattering by suspended materials, particularly for the $0.75-\mu \mathrm{m}$ band. Under these conditions, the channels in this spectral region have limited use for retrieving information on atmospheric aerosols. Because the SeaWiFS types of algorithms derive aerosol information from channels in the $0.75-0.865 \mu \mathrm{m}$ spectral range, these algorithms cannot be easily adapted for operational retrieval of water leaving radiances over coastal waters. In view of this limitation, we designed a spectrum-matching algorithm [20] that allowed the use of channels in shortwave IR (SWIR) spectral regions between 1 and $2.5 \mu \mathrm{m}$, where the turbid waters are much darker, for the estimates of aerosol models and optical depths. Our algorithm was based on Robert Fraser's radiative transfer formulation and algorithm [24,25]. The adoption of the Fraser formulation permits the simultaneous matching 
between measured radiances of several bands centered at different wavelengths with those from theoretical simulations and results in more stable estimates of aerosol models and optical depths.

In our algorithm, we express radiances in reflectance units. We adopt the standard definition of apparent reflectance $\rho^{*}{ }_{\text {obs }}$ at a satellite level for a given wavelength as $[20,26]$

$$
\rho^{*}{ }_{o b s}=\pi L_{o b s} /\left(\mu_{o} E_{o}\right),
$$

where $L_{o b s}$ is the radiance of the ocean-atmosphere system measured by a satellite instrument, $\mu_{0}$ the cosine of solar zenith angle, and $E_{o}$ the downward solar irradiance at the top of the atmosphere when the solar zenith angle is equal to zero. Neglecting the interactions between atmospheric gaseous absorption and molecular and aerosol scattering, $\rho_{\text {obs }}^{*}$ can be expressed as $[20,26]$

$$
\rho^{*}{ }_{o b s}=T_{g}\left[\rho^{*}{ }_{a t m+s f c}+\rho_{w} t_{d} t_{u} /\left(1-s \rho_{w}\right)\right.
$$

where $T_{g}$ is the total atmospheric gaseous transmittance on the Sun-surface-sensor path, $\rho^{*}{ }_{a t m+s f c}$ the reflectance resulted from scattering by the atmosphere and specular reflection by ocean surface facets, $t_{d}$ the downward transmittance (direct + diffuse), and $t_{u}$ the upward transmittance, $s$ the spherical albedo that takes account of reflectance of the atmosphere for isotropic radiance incident at its base, and $\rho_{w}$ the water leaving reflectance.

Solving Equation (2) for $\rho_{w}$ yields

$$
\rho_{w}=\left(\rho_{o b s}^{*} / T_{g}-\rho_{a t m+s f c}^{*}\right) /\left[t_{d} t_{u}+s\left(\rho_{o b s}^{*} / T_{g}-\rho_{a t m+s f c}^{*}\right)\right]
$$

Given a satellite measured radiance, the water leaving reflectance can be derived according to Equations (1) and (3) provided that the other quantities in the righthand side of Equation (3) can be modeled theoretically. Because of the availability of the vector radiative transfer code, the proper atmospheric layering structure in this code (up to 80 layers with proper mixing of aerosol particles and atmospheric molecules in each layer), and the treatment of wind-roughened water surfaces, we have used a modified version of Ahmad and Fraser code [27] to generate lookup tables used in our retrieving algorithm. Specifically, we use the code to generate the quantities $\rho^{*}{ }_{a t m+s f c}, t_{d}, t_{u}$, and $s$ in Equation (2). Lookup tables for 14 wavelengths between 0.39 and $2.5 \mu \mathrm{m}$ in atmospheric "window" regions, sets of aerosol models, optical depths, solar and view angles, and surface wind speeds have been generated. Aerosol models, similar to those used in the SeaWiFS algorithm, are used during our table generation. A sophisticated line-by-line based atmospheric transmittance code is used in our algorithm to calculate contiguous atmospheric gaseous transmittance spectra $\left(T_{g}\right)$.

We match the satellite measured "apparent reflectances" of selected NIR and SWIR bands with those pre-computed apparent reflectances for different aerosol models and optical depths. The simulated lookup table apparent reflectances (after interpolation) have step sizes of 0.001 or smaller. The fine step sizes are smaller than the noise levels of satellite measured data. During the retrieving process for a given pixel, we search through all possible combinations of aerosol models and optical depths in lookup tables, and find the best match of the aerosol model and optical depth that minimizes the sum of the squared differences between the measured apparent reflectances (two or more NIR and SWIR bands) and those from theoretical simulations. Because of large computer memory sizes for storing lookup tables and because of the array processing capability of our codes written in Fortran 90 , our table searching and minimization process is very fast. We did not need to implement an additional numerical optimization method, such as the commonly used gradient descent method, to speed up the table searching and minimization process. For example, in one test case, we processed one hyperspectral data set having 614 pixels in the cross-track direction, 1024 lines in the along-track direction, and 224 spectral bands, using a Macbook computer having a $2.9 \mathrm{GHz}$ Dual-Core Intel Core i5 processor. It took about 500 megabytes of memory and 140 seconds of computer time to finish the data processing. Our hyperspectral atmospheric correction algorithm has been tested with images 
acquired with a number of instruments, including the airborne visible infrared imaging spectrometer (AVIRIS) [19] from an ER-2 aircraft at an altitude of $20 \mathrm{~km}$.

We also adapted the hyperspectral ocean atmospheric correction algorithm for processing multi-channel imagery, such as those acquired with the Terra and Aqua MODIS instruments [28]. In the MODIS algorithm, the lookup tables corresponding to MODIS wavelengths are obtained through linear interpolation of the tables generated for the hyperspectral atmospheric correction algorithm. The lookup table quantities, $\rho_{a t m+s f c}^{*}, t_{d}, t_{u}$, and $s$, are functions of wavelength, solar zenith angle, view zenith angle, relative azimuth angle, aerosol model, optical depth, relative humidity, and surface wind speed, respectively. For MODIS data, each pixel's solar zenith angle, view zenith angle, and relative azimuth angle are variable because of the large swath width ( $2800 \mathrm{~km}$ for one scan line). In order to speed up the retrieving process, the storage order for different MODIS lookup table quantities (such as wavelengths, particle size distributions, solar and view angles, etc.) is optimized. Because MODIS has water vapor bands centered near $0.94 \mu \mathrm{m}$, we derive water vapor values from MODIS data on the pixel by pixel basis, and then use the derived water vapor values to calculate water vapor transmittances for other bands used for retrievals. Climatological atmospheric ozone, carbon dioxide, and methane amounts are used for modeling relevant gaseous transmittances. Similarly, we developed a VIIRS ocean version of algorithm. The VIIRS channels centered at 1.24, 1.61, and $2.25 \mu \mathrm{m}$ with proper modeling of atmospheric $\mathrm{CO}_{2}$ and $\mathrm{CH}_{4}$ absorption effects and a spectrum-matching technique were used for atmospheric corrections.

Based on our experience in developing MODIS and VIIRS versions of atmospheric correction algorithms, we have recently developed spectrum-matching versions of ABI and AHI multi-channel atmospheric correction algorithms. The main tasks in the ABI and AHI algorithm development were to generate proper transmittance tables of atmospheric gases, including those of ozone, water vapor, carbon dioxide, and methane, for $\mathrm{ABI}$ and $\mathrm{AHI}$ bands in the $0.4-2.3 \mu \mathrm{m}$, as illustrated in Figure 2. The spectrum-matching technique is also used for atmospheric corrections and for the subsequent retrieval of water leaving reflectances from ABI and AHI data. Figure 4 illustrates the spectrum-matching technique.

Figure 4a is a false color RGB image (Red: 0.637; Green: 0.864; Blue: $0.471 \mu \mathrm{m}$ ) acquired at UTC 1100 on December 17, 2018 with ABI on board the GOES-16 satellite platform. The image covered algae blooming areas off the coast of Argentina in the Atlantic Ocean. Figure $4 \mathrm{~b}$ illustrates the spectrum-matching technique for water leaving reflectance retrievals. The red line (marked with the plus symbol) in Figure $4 \mathrm{~b}$ shows the apparent reflectances for 5 ABI bands for a water pixel located at the center of the red square in the right side of the Figure 4a image. The 0.86-, 1.61-, and 2.24- $\mu \mathrm{m}$ bands were used for the estimation of aerosol model and optical depth by minimizing the sum of the squared differences between the measured data and calculated data during the spectrum-matching process. The estimated aerosol model and optical depth were extracted back to the ABI blue and red bands. The green line (marked with “*”) shows the estimated atmospheric path radiances in reflectance

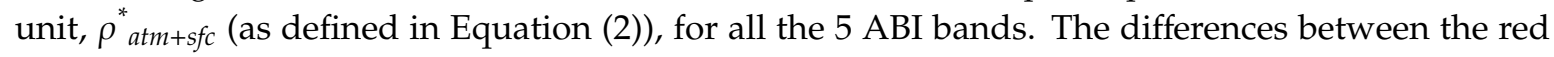
line and the green line are proportional to water leaving reflectances (see Equation (3)). The blue line (marked with the triangle symbol) shows the water leaving reflectances of ABI bands for the algae pixel. The water leaving reflectance value for the blue band is close to 0.1 , indicating that the pixel is highly reflecting in the blue spectral region. 
(A) ABI False Color Image (UTC 1100)

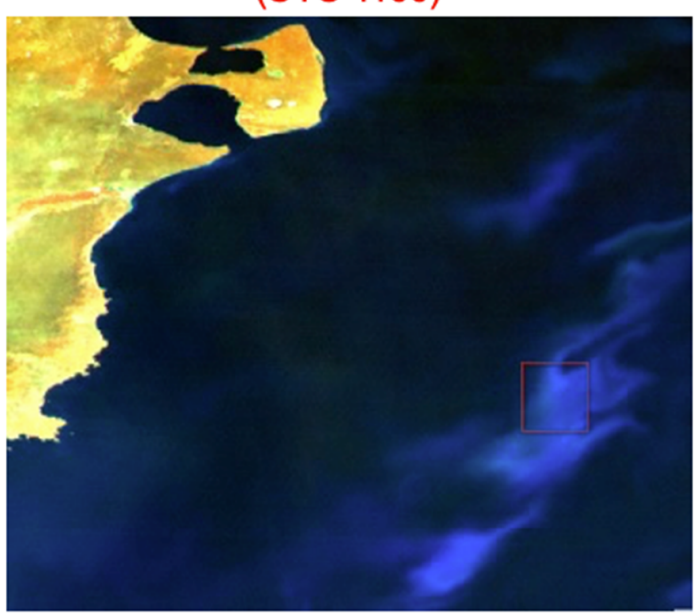

(C)

Water Refl. Image (UTC 1100)
(B) Sample Water Refl. Retrieval

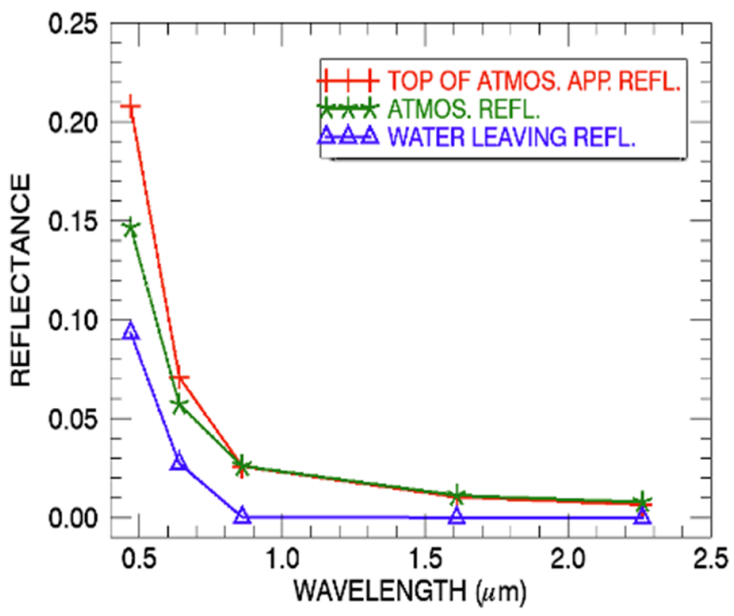

(D)

Water Refl. Image (UTC 1800)

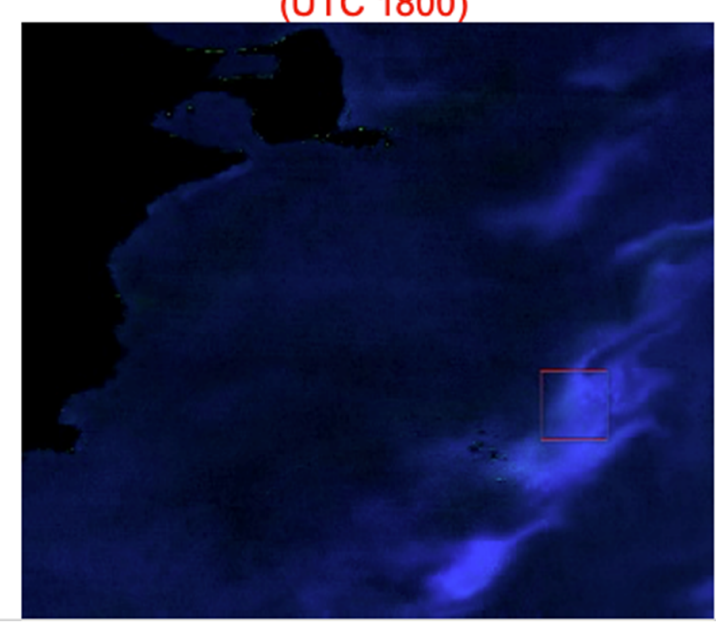

Figure 4. (A) - a false color ABI image acquired at UTC 1100 on December 17, 2018 off the coast of Argentina covering algae blooming regions; (B) —spectral plot for a bright pixel for top of atmosphere (TOA) apparent reflectances (red line), atmospheric reflectances (green line), and water leaving reflectances (blue line); (C) - the retrieved false color water leaving reflectance image for the UTC 1100 scene; and (D) - the derived false color water leaving reflectance image for the UTC 1800 scene.

\section{Results}

We have selected three examples to demonstrate the capabilities in deriving water leaving reflectances from $\mathrm{ABI}$ and $\mathrm{AHI}$ data. The selection of the ABI and $\mathrm{AHI}$ cases was based on $\mathrm{ABI}$ and AHI time sequences of movie images available from a public web site associated with the Cooperative Research Program at Colorado State University. The first example is for the ABI scene covering a major blooming event off the coast of Argentina (see Figure 4a). The second example is for an ABI scene over the Gulf of Mexico where large amounts of sediments were discharged from rivers into the Gulf of Mexico. The third case is for a Japanese AHI scene for the coastal areas of Japan, Korea Peninsula, and eastern part of China, where very turbid coastal waters were present.

\subsection{ABI Scene Over Coastal Area of Argentina, December 17, 2018}

The ABI instrument on GOES-16 captured a major chlorophyll blooming event occurred in the middle of December of 2018. As described in Section 2, Figure 4a is a false color RGB image acquired at UTC 1100 on December 17 over algae blooming areas off the coast of Argentina in the Atlantic Ocean. 
Figure $4 \mathrm{~b}$ shows the results of matching technique for water leaving reflectance retrievals from ABI data. Because ABI didn't have a true green band, it is not possible to observe the green reflectance peak centered near $0.55 \mu \mathrm{m}$ in the Figure $4 \mathrm{~b}$ water leaving reflectance curve. Figure $4 \mathrm{c}$ is the false color RGB image processed from the retrieved water leaving reflectances of the Figure 4a UTC 1100 scene. In principle, water leaving reflectance images, similar to the one illustrated in Figure 4c, at a time interval of approximately 10 minutes can be obtained from ABI data because of the rapid repeating cycle of ABI measurements. Figure 4d shows another false color ABI water leaving reflectance image for UTC 1800. Although the NASA MODIS instrument onboard the Aqua Spacecraft acquired image at UTC 1755 over the same area and covered the same chlorophyll patches, the NASA operational MODIS algorithm didn't make ocean color retrievals over areas containing the chlorophyll features in the MODIS scene. As a result, it is not possible to make quantitative comparisons between our retrieval results with those from the NASA operational algorithm. Nevertheless, the images and line plots in Figure 4 demonstrate that water leaving reflectance images can be retrieved from ABI data with our ABI version of multi-channel atmospheric correction algorithm.

\subsection{ABI Scene Over Coastal Area of Gulf of Mexico, March 20, 2019}

Figure 5 shows another example of water leaving reflectance retrieval from ABI data. The data sets were acquired on March 20, 2019 off the coastal area of Louisiana and Texas. At the time, large amounts of sediments were discharged from rivers into the Gulf of Mexico. Figure $5 a, b$ is a false color RGB image (R: 0.637; G: 0.864; B: $0.471 \mu \mathrm{m}$ ) acquired at UTC 1730 and 1930, respectively. The brownish-colored areas contained large amount of sediments. Figure $5 c, d$ is the corresponding false color water leaving reflectance images. The sediment-dominated areas were picked up very nicely in the Figure $5 \mathrm{c}, \mathrm{d}$. The ABI 1.61-, and 2.24- $\mu \mathrm{m}$ bands were used during atmospheric corrections. Figure 5e illustrates the atmospheric correction for one sediment-dominated pixel located near the center of the rectangle outlined in the Figure 5b,d images. The six points marked with "** are the top of atmosphere (TOA) apparent reflectances for the six ABI bands. The five points marked with small green-colored triangles are the retrieved water leaving reflectances for the pixel. The atmosphere-corrected $0.637-\mu \mathrm{m}$ red band reflectance is about 0.12 , which indicates that the sediment-dominated pixel is highly reflecting in the red band. Although the Aqua MODIS instrument had a good overpass over the same area at UTC 1925, the sediment-dominated areas were masked out by the NASA MODIS atmospheric correction algorithm and no water leaving reflectance retrievals were made. Figure 5 demonstrates that ABI data can be used for water leaving reflectance retrievals over sediment-dominated areas. The data products from ABI can be complimentary to the existing NASA polar-orbiting dominated ocean color data products, particularly over turbid coastal waters.

For comparison and validation purposes, we have also retrieved water leaving reflectances from a MODIS data set acquired at UTC 1925 on the same day over similar areas. Figure 6a is a true color MODIS RGB image. Figure $6 \mathrm{~b}$ is a false color image (R: $0.645 \mu \mathrm{m}$; G: $0.845 \mu \mathrm{m}$; B: $0.466 \mu \mathrm{m}$ ) of the same scene. Figure $6 \mathrm{~b}$ covers nearly the same area as that of Figure $5 \mathrm{~b}$. Major land and water surface features in both images are approximately the same. However, because the Aqua spacecraft has a declination angle of 98.5 degree and because no spatial registration is made between the MODIS image and the ABI image, the small turbid water areas in the upper right portion of Figure $6 \mathrm{~b}$ are not covered in Figure 5b. Figure $6 \mathrm{c}$ is the false color water leaving reflectance image (R: $0.645 \mu \mathrm{m}$; G: $0.845 \mu \mathrm{m}$; B: $0.466 \mu \mathrm{m})$. Based on visual inspection of images in Figures $6 \mathrm{c}$ and $5 c$, we selected nearly same spatial areas and extracted spectral reflectances. Figure $6 \mathrm{~d}$ shows water leaving reflectances derived from ABI (dashed green curve) and from MODIS data (solid line) using narrow bands near 0.86, 1.61, and $2.25 \mu \mathrm{m}$. By comparing the two curves in Figure $6 \mathrm{~d}$, it is seen that the ABI band reflectance values agreed quite well with those of the corresponding MODIS band values. The good agreement partially validated our ABI version of the atmospheric correction algorithm. It should be pointed out that, because MODIS has more narrow bands, the MODIS curve provides more spectral information than the ABI curve. For example, MODIS has a band centered near $0.52 \mu \mathrm{m}$ and this band has much larger 
reflectance value than the two nearby bands, while ABI does not have a band centered near $0.52 \mu \mathrm{m}$ and has less capability in charactering the spectral reflectance properties of water surfaces.
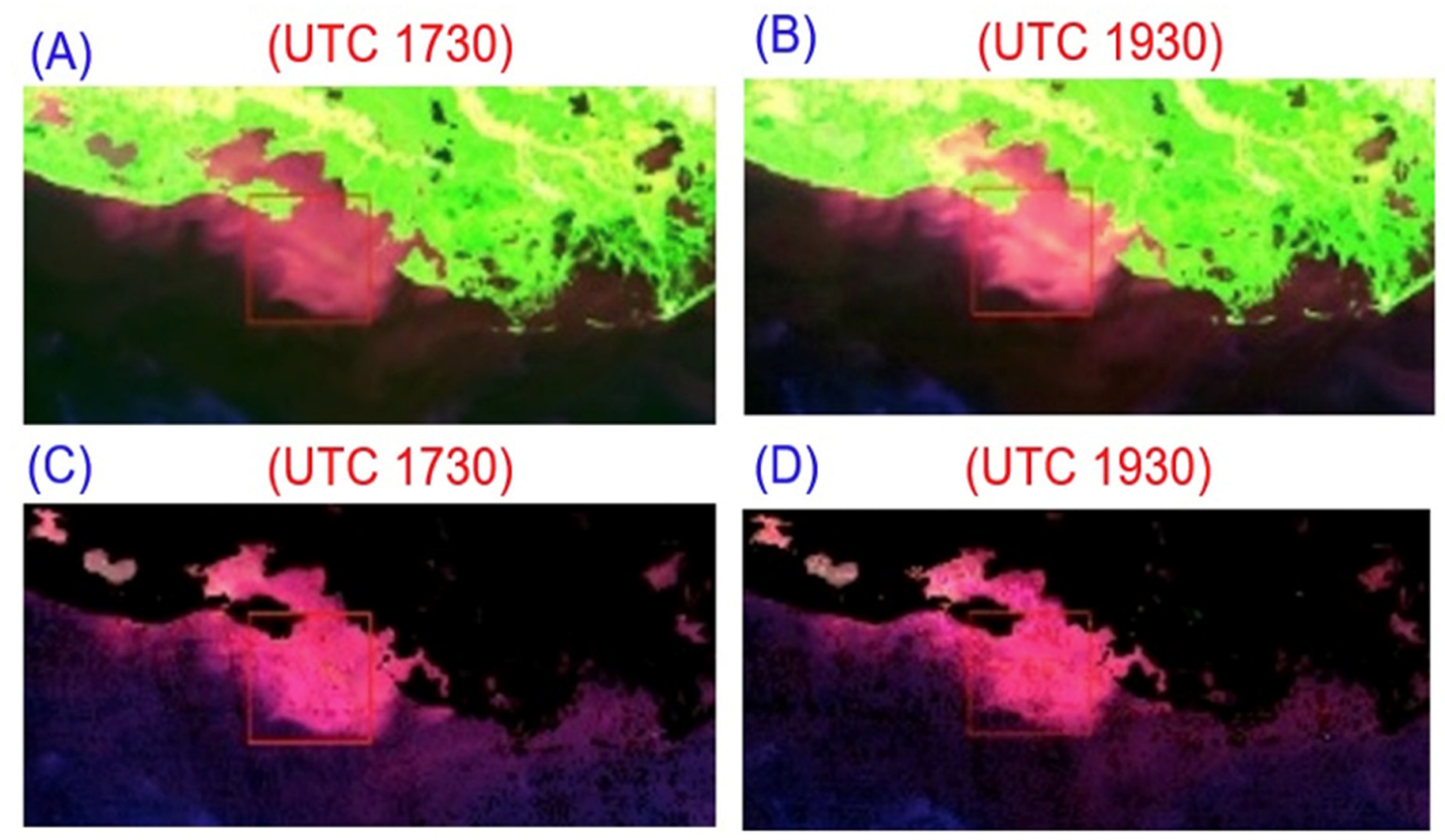

$(\mathrm{E})$

(UTC 1930)

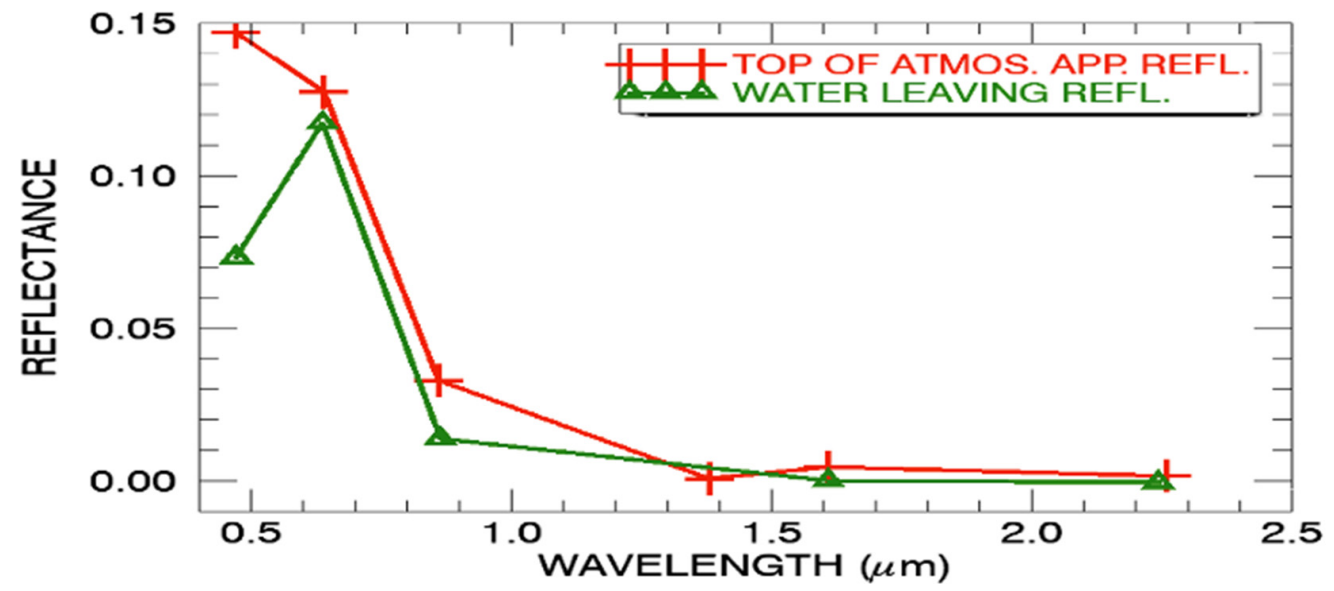

Figure 5. (A,B): false color ABI images acquired at UTC 1730 and 1930, respectively on March 20, 2019 near the Gulf of Mexico; (C,D): the corresponding derived water surface reflectance images; $(\mathrm{E})$ : spectral plot for a pixel before and after atmospheric corrections. 
(A) MODIS RGB (UTC 1925)

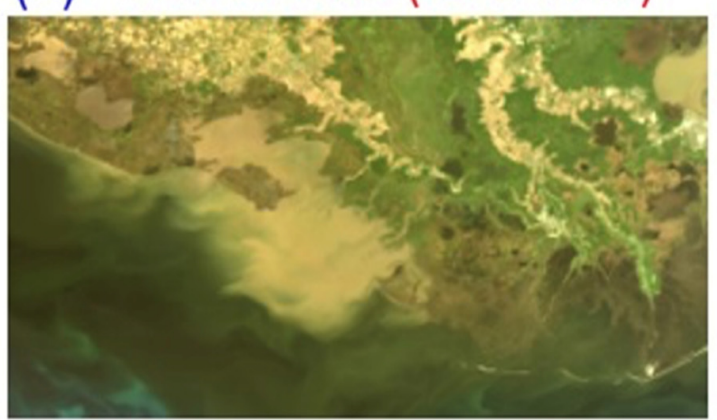

(C) REFLECTANCE IMAGE

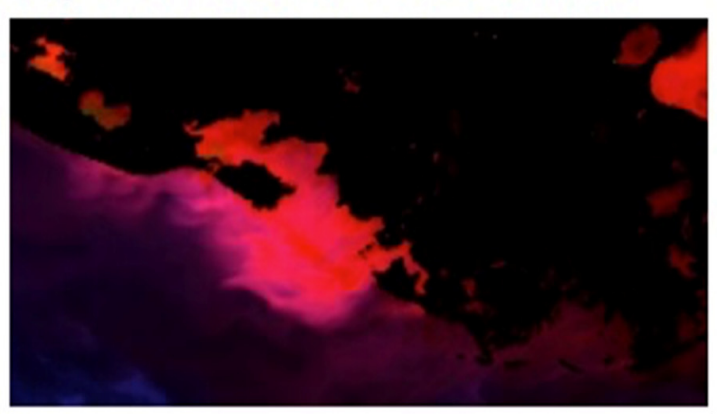

(B) MODIS False Color Image

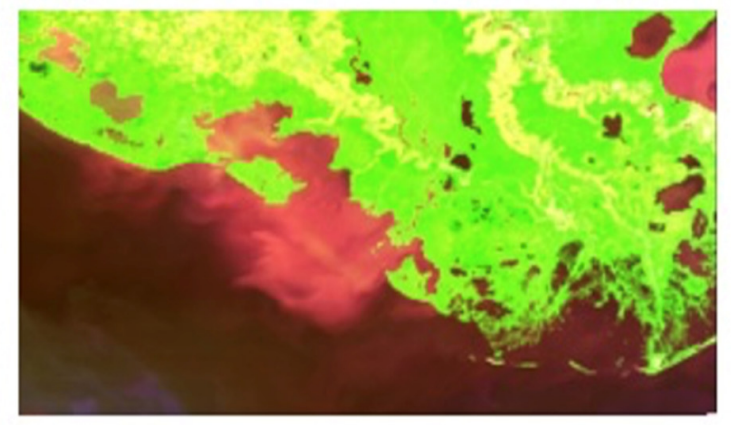

(D) SPECTRAL REFLECTANCE

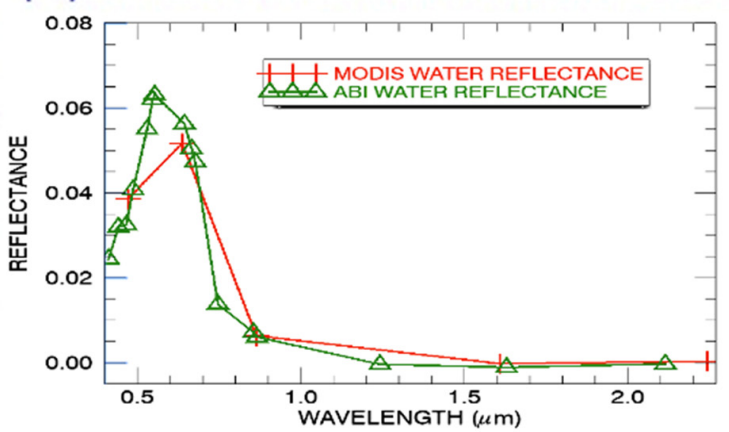

Figure 6. (A,B) - true color and false color moderate resolution imaging spectroradiometer (MODIS) images acquired near the Gulf of Mexico at UTC 1925 on March 20, 2019; (C)—the corresponding derived water surface reflectance images; and (D) - water leaving reflectances derived from ABI (dashed green curve) and from MODIS data (solid line).

\subsection{AHI Scene Over Eastern Asia, May 28, 2017}

Figure 7 shows an example of water leaving reflectance retrievals from the Japanese AHI data measured on May 28, 2017 over part of Japan, Korea, and eastern China. Figure 7a is the RGB image (R: 0.64-; G: 0.51-; B: 0.47- $\mu \mathrm{m}$ ) acquired at UTC 0200. It can be difficult to distinguish between bright coastal waters in these visible band images, particularly in the left portion of the scene. Figure $7 \mathrm{~b}$ shows the AHI image for the $1.61-\mu \mathrm{m}$ band. A large inland lake (Lake Taihu located near the lower left corner), rivers, and coastal waters are quite dark in this image because of strong liquid water absorption at $1.61 \mu \mathrm{m}$. Through several trials and tests, we decided to select a $1.61-\mu \mathrm{m}$ band threshold. Pixels with the $1.61-\mu \mathrm{m}$ band TOA apparent reflectance values greater than 0.03 were classified as land or cloudy pixels. These pixels were masked out in our water leaving reflectance data product. Figure $7 \mathrm{c}$ shows the retrieved water leaving reflectance image for the scene. With the SWIR spectrum-matching algorithm, we are able to do retrievals over the deep ocean waters, bright coastal waters, and inland lakes and rivers. By comparing Figure 7c with Figure 2b, it seen that we have greatly expanded the retrievals over very turbid water areas in eastern part of China and around Korea Peninsula. In particular, we are able to do retrievals over Lake Taihu, which is seen in the lower left part of Figure 7c. Figure $7 \mathrm{~d}$ illustrates the atmospheric correction for one turbid water pixel in west coastal area of the Korea Peninsula using two narrow channels centered near 1.61 and $2.25 \mu \mathrm{m}$ for aerosol retrievals. The six points marked with the "+" symbol are the TOA apparent reflectances for the six AHI bands. The six points marked with small diamonds are the retrieved water leaving reflectances for the pixel. The near zero surface reflectance values for the AHI bands centered near 0.865, 1.61, and $2.25 \mu \mathrm{m}$ demonstrate that proper minimization is made during the spectrum-matching process. 


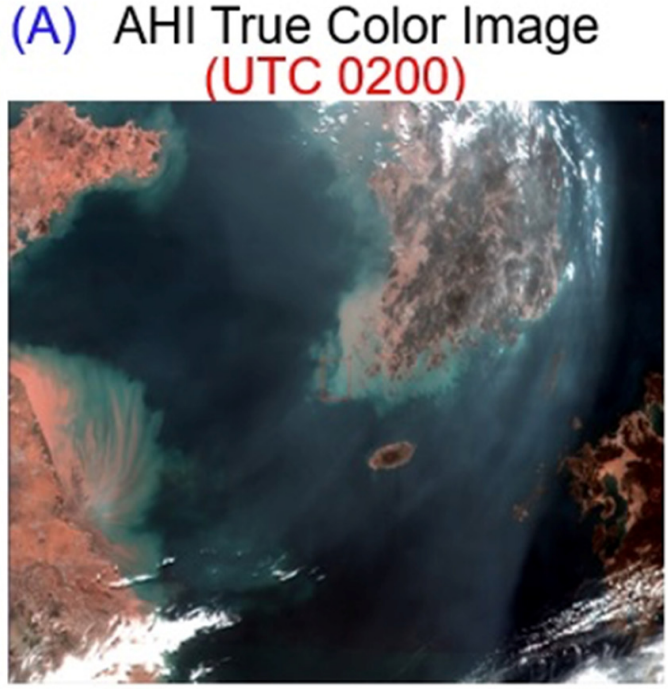

(C) AHI Water Refl. Image (UTC 0200)

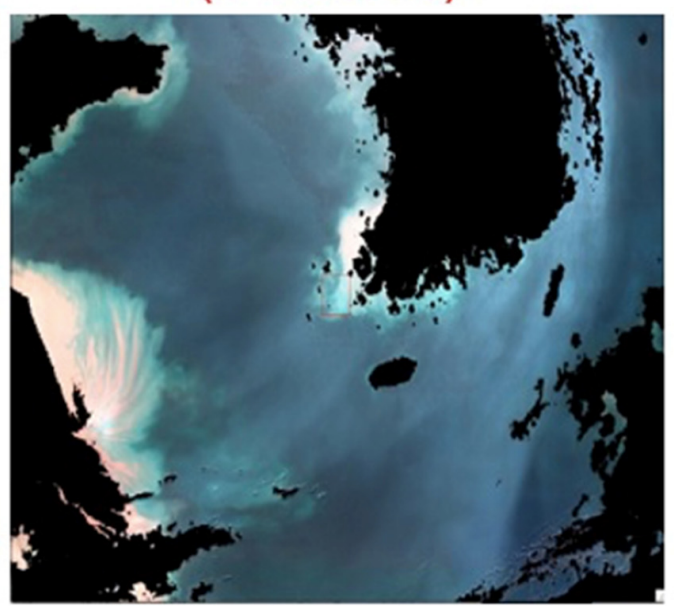

(B) AHI 1.61- $\mu \mathrm{m}$ Image (UTC 0200)

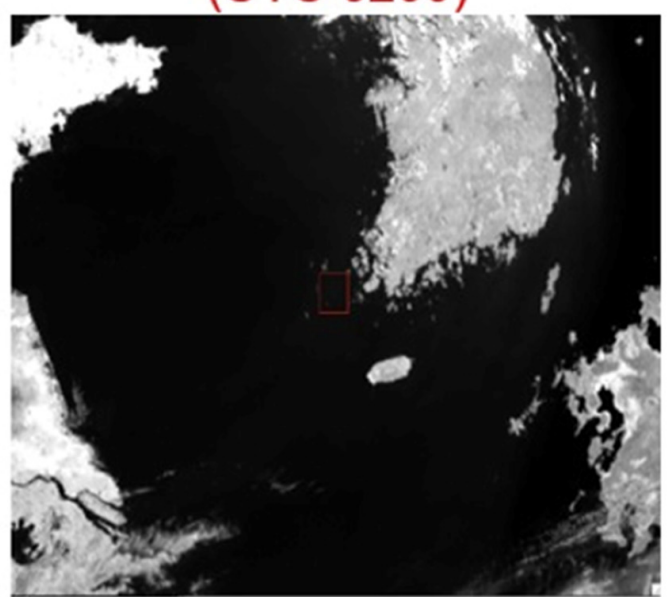

(D) Sample TOA Refl. \& Surface Refl.

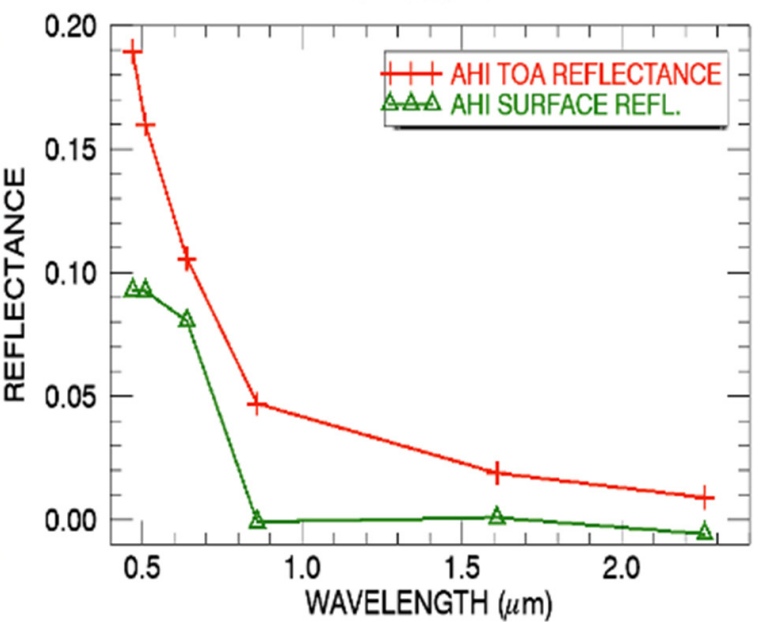

Figure 7. (A) - a true color AHI image acquired at UTC 0200 on May 28, 2017 over part of Japan, Korea, and eastern China; (B) - the 1.61- $\mu \mathrm{m}$ AHI B/W image; (C) — the retrieved true color water leaving reflectance image; and (D) — spectral plot for a bright pixel for TOA apparent reflectances marked with the "+"symbols and for the corresponding surface reflectances marked with small diamonds.

\section{Discussions}

It should be pointed out that water leaving reflectance retrievals, such as those showing in Figures 4,5 and 7 , are made on the pixel by pixel basis with our spectrum-matching versions of ABI and $\mathrm{AHI}$ atmospheric correction algorithms. No spatial and temporal averaging of ABI and AHI data is required during the retrievals. Similar retrievals with the SeaWiFS-type of algorithm adopted for AHI data processing by Murakami [7] required temporal averaging on the hourly basis. In the original operational SeaWiFS algorithm, spatial averaging of the 0.75 - and $0.86-\mu \mathrm{m}$ bands was made for improving signal to noise ratios of the two atmospheric correction bands. The calculation of two band ratios magnifies the noise by a factor of two [10]. The spectrum-matching algorithms described here do not need the calculation of two-band ratios. In fact, if two bands are used in the spectrum-matching process (e.g., Figures 5 and 7), the signal to noise ratio is increased by a factor of square root of two. If three bands are used in the matching process (e.g., Figure 4), the signal to noise ratio is increased by square root of three [10]. Therefore, the use of spectrum-matching algorithms for atmospheric corrections and for derivation of water leaving reflectances in the visible requires less signal to noise 
ratios of the original satellite-measured data than the use of SeaWiFS-type of two-band ratio algorithms. This fine point is very important to atmospheric corrections for the present generation of geostationary weather satellite data, because the relevant instruments were not geared for ocean color measurements with exceedingly high signal to noise ratios. In addition, performing spatial and temporal averaging to improve signal to noise ratios can sometimes be difficult. For example, during a time interval of one hour for the day May 28, 2017 (see Figure 6), the aerosol properties over a given area in the Figure 6 scene changed quite a bit because of the movement of a dust storm through the area. Temporal averaging is not quite suited for improving signal to noise ratios for atmospheric correction purposes for this particular day.

The details on our radiative transfer simulations [27], generation of lookup tables, and spectrum-matching processes were previously described in our hyperspectral ocean version of atmospheric correction algorithm [20] and multi-channel MODIS algorithm [28]. The water leaving reflectance retrieving results from MODIS data were verified with measurements with a portable field spectrometer over surface stations in Bahamas Banks and Florida Bay area [28]. The results were also compared with those from the NASA operational MODIS algorithm. Because the lookup tables used in our $\mathrm{ABI}$ and $\mathrm{AHI}$ algorithms were obtained through interpolation of the same hyperspectral lookup tables simulated with the Ahmed and Fraser radiative transfer code [27] and because our hyperspectral and MODIS multi-spectral retrieving results were previously validated, we feel that it is not absolutely necessary to have additional validation of our several sample retrieving cases from $A B I$ and AHI data. In addition, we are now having practical difficulties in obtaining additional ABI and AHI data sets for more case studies, because the public ftp access is no longer permitted at our computing facility.

In the commonly used SeaWiFS types of ocean version of atmospheric correction algorithms, the atmospheric path radiances in reflectance unit after subtraction of Rayleigh scattering effects are stored in lookup tables, such as the tables used in the NASA operational SeaWiFS, MODIS, and VIIRS algorithms. Under very clear atmospheric conditions, the Rayleigh-subtracted atmospheric path reflectances for bands centered near 1.24, 1.61, and $2.25 \mu \mathrm{m}$ can be very small and close to zero. The extension of the SeaWiFS types of 2-band ratio algorithms to SWIR band pairs, such as the 1.24- and 1.61- $\mu \mathrm{m}$ band pair and the 1.24- and $2.25-\mu \mathrm{m}$ band pair, can encounter the problems of zero divided by zero or zero divided by negative numbers due to the presence of noises in measured SWIR band data. As a result, the use of 2-SWIR band ratio technique for the estimates of aerosol models and optical depths during atmospheric correction processes can be problematic. The multi-channel ocean color research community does not seem to well understand the intrinsic problems [29].

\section{Summary}

We have developed atmospheric correction algorithms for retrieving water leaving reflectances from $\mathrm{ABI}$ and $\mathrm{AHI}$ data using spectrum-matching techniques. Our spectrum-matching algorithms reduced significantly the signal to noise ratio requirements for atmospheric correction channels in comparison with those required with the widely used SeaWiFS types of two-channel ratio algorithms by the current multi-channel ocean color research community. We have demonstrated using three case studies that water leaving reflectance retrievals can be made from satellite-measured ABI and AHI data with our spectrum-matching versions of atmospheric correction algorithms. Our algorithms, if implemented onto operational computing facilities, can be complimentary to current operational ocean versions of atmospheric correction algorithms in the area of improving spatial coverage over turbid coastal waters.

Author Contributions: B.-C.G. made initial observations of chlorophyll blooming features and suspended sediment features from ABI and AHI data sets, and developed spectrum-matching versions of algorithms for retrieving water leaving reflectances from $\mathrm{ABI}$ and $\mathrm{AHI}$ data. R.-R.L. carried out retrievals and detailed data analysis. All authors have read and agreed to the published version of the manuscript.

Funding: This research is partially supported by the US Office of Naval Research and by a research grant managed by Jared K. Entin at the Science Mission Directorate of National Aeronautics and Space Administration. 
Acknowledgments: The authors are grateful to Weile Wang affiliated with California State University in Monterey and NASA Ames Research Center for providing the ABI and AHI data in HDF4 format used in this study. The authors are also grateful to Pengwang Zhai of University of Maryland at Baltimore County for useful discussions.

Conflicts of Interest: The authors declare no conflict of interest.

\section{References}

1. Chen, X.; Shang, S.; Lee, Z.; Qi, L.; Yan, J.; Li, Y. High-frequency observation of floating algae from AHI on Himawari-8. Remote. Sens. Environ. 2019, 227, 151-161. [CrossRef]

2. Neukermans, G.; Ruddick, K.; Bernard, E.; Ramon, D.; Nechad, B.; Deschamps, P.-Y. Mapping total suspended matter from geostationary satellites: A feasibility study with SEVIRI in the Southern North Sea. Opt. Express 2009, 17, 14029-14047. [CrossRef] [PubMed]

3. Neukermans, G.; Ruddick, K.G.; Greenwood, N. Diurnal variability of turbidity and light attenuation in the southern North Sea from the SEVIRI geostationary sensor. Remote. Sens. Environ. 2012, 124, 564-580. [CrossRef]

4. Martin, G.; Criscione, J.C.; Cauffman, S.A.; Davis, M.A. Geostationary Operational Environmental Satellites (GOES): R series hyperspectral environmental suite (HES) overview. Remote Sens. 2004, 5570, $173-183$. [CrossRef]

5. King, M.D.; Menzel, W.P.; Kaufman, Y.J.; Tanré, D.; Gao, B.C.; Platnick, S.; Hubanks, P.A. Cloud and aerosol properties, precipitable water, and profiles of temperature and humidity from MODIS. IEEE Trans. Geosci. Remote Sens. 2003, 41, 442-458. [CrossRef]

6. Lee, T.F.; Nelson, C.S.; Dills, P.; Riishojgaard, L.P.; Jones, A.; Li, L.; Hoffman, C. NPOESS: Next-generation operational global earth observations. Bull. Amer. Meteorol. Soc. 2010, 91,727-740. [CrossRef]

7. Murakami, H. Ocean color estimation by Himawari-8/AHI. In Proceedings of the of SPIE Asia-Pacific Remote Sensing, New Delhi, India, 4-7 April 2016; Volume 9878, p. 987610.

8. Fukushima, H.; Toratani, M.; Tanaka, A.; Chen, W.-Z.; Murakami, H.; Frouin, R.J.; Mitchell, B.G.; Kahru, M. ADEOS-II/GLI ocean-color atmospheric correction: Early phase result. In Proceedings of theOptical Science and Technology, SPIE's 48th Annual Meeting, San Diego, CA, USA, 3-8 August 2003; Volume 5155, pp. 91-99. [CrossRef]

9. Gordon, H.R.; Wang, M. Retrieval of water-leaving radiance and aerosol optical thickness over the oceans with SeaWiFS: A preliminary algorithm. Appl. Opt. 1994, 33, 443. [CrossRef]

10. Bevington, P.R.; Robinson, D.K. Data Reduction and Error Analysis for the Physical Sciences, 3rd ed.; McGraw-Hill Inc.: New York, NY, USA, 2003; pp. 36-46.

11. Ryu, J.H.; Han, H.-J.; Cho, S.; Park, Y.-J.; Ahn, Y.-H. Overview of geostationary ocean color imager (GOCI) and GOCI fata processing system (GDPS). Ocean Sci. J. 2012, 47, 223-233. [CrossRef]

12. Ahn, J.-H.; Park, Y.-J.; Ryu, J.-H.; Lee, B.; Oh, I.S. Development of atmospheric correction algorithm for Geostationary Ocean Color Imager (GOCI). Ocean Sci. J. 2012, 47, 247-259. [CrossRef]

13. Bailey, S.W.; Franz, B.A.; Werdell, P.J. Estimation of near-infraredwater-leaving reflectance for satellite ocean color data processing. Opt. Express 2010, 18, 7521-7527. [CrossRef]

14. Shi, W.; Wang, M. Satellite views of the Bohai Sea, Yellow Sea, and East China Sea. Prog. Oceanogr. 2012, 104, 30-45. [CrossRef]

15. Ruddick, K.G.; Ovidio, F.; Rijkeboer, M. Atmospheric correction of SeaWiFS imagery for turbid coastal and inland waters. Appl. Opt. 2000, 39, 897-912. [CrossRef] [PubMed]

16. Doxaran, D.; Lamquin, N.; Park, Y.-J.; Mazeran, C.; Ryu, J.-H.; Wang, M.; Poteau, A. Retrieval of the seawater reflectance for suspended solids monitoring in the East China Sea using MODIS, MERIS and GOCI satellite data. Remote. Sens. Environ. 2014, 146, 36-48. [CrossRef]

17. Huang, X.; Zhu, J.; Han, B.; Jamet, C.; Tian, Z.; Zhao, Y.; Li, J.; Li, T. Evaluation of Four Atmospheric Correction Algorithms for GOCI Images over the Yellow Sea. Remote. Sens. 2019, 11, 1631. [CrossRef]

18. Frouin, R.J.; Franz, B.A.; Ibrahim, A.; Knobelspiesse, K.; Ahmad, Z.; Cairns, B.; Chowdhary, J.; Dierssen, H.M.; Tan, J.; Dubovik, O.; et al. Atmospheric Correction of Satellite Ocean-Color Imagery During the PACE Era. Front. Earth Sci. 2019, 7. [CrossRef] 
19. Green, R.O.; Eastwood, M.L.; Sarture, C.M.; Chrien, T.G.; Aronsson, M.; Chippendale, B.J.; Faust, J.A.; Parvi, B.E.; Chovit, C.J.; Solis, M.; et al. Imaging spectrometry and the Airborne Visible/Infrared Imaging Spectrometer (AVIRIS). Remote Sens. Environ. 1998, 65, 227-248. [CrossRef]

20. Gao, B.; Montes, M.J.; Ahmad, Z.; Davis, C.O. Atmospheric correction algorithm for hyperspectral remote sensing of ocean color from space. Appl. Opt. 2000, 39, 887-896. [CrossRef]

21. Siegel, D.A.; Wang, M.; Maritorena, S.; Robinson, W. Atmospheric correction of satellite ocean color imagery: The black pixel assumption. Appl. Opt. 2000, 39, 3582-3591. [CrossRef]

22. Arnone, R.A.; Martinolich, P.; Gould, R.W.; Syder, M.; Stumps, R.P. Coastal optical properties using SeaWiFS. In Proceedings of the Ocean Optics XIV Conference, Kailua-Kona, Hawaii, 10-13 November 1998.

23. Davis, C.O.; Bowles, J.; Leathers, R.A.; Korwan, D.; Downes, T.V.; Snyder, W.A.; Rhea, W.J.; Chen, W.; Fisher, J.; Bissett, P.; et al. Ocean PHILLS hyperspectral imager: Design, characterization, and calibration. Opt. Express 2002, 10, 210-221. [CrossRef]

24. Fraser, R.S.; Mattoo, S.; Yeh, E.-N.; McClain, C.R. Algorithm for atmospheric and glint corrections of satellite measurements of ocean pigment. J. Geophys. Res. Space Phys. 1997, 102, 17107-17118. [CrossRef]

25. Fraser, R.S.; Ferrare, R.A.; Kaufman, Y.J.; Markham, B.; Mattoo, S. Algorithm for atmospheric corrections of aircraft and satellite imagery. Int. J. Remote. Sens. 1992, 13, 541-557. [CrossRef]

26. Tanre, D.; DeRoo, C.; Duhaut, P.; Herman, M.; Morcrette, J.J.; Perbos, J.; Deschamps, P.Y. Technical note Description of a computer code to simulate the satellite signal in the solar spectrum: The $5 \mathrm{~S}$ code. Int. J. Remote Sens. 1990, 11, 659-668. [CrossRef]

27. Ahmad, Z.; Fraser, R.S. An Iterative Radiative Transfer Code for Ocean-Atmosphere Systems. J. Atmospheric Sci. 1982, 39, 656-665. [CrossRef]

28. Gao, B.-C.; Montes, M.J.; Li, R.-R.; Dierssen, H.M.; Davis, C.O. An atmospheric correction algorithm for remote sensing of bright coastal waters using MODIS land and ocean channels in the solar spectral region. IEEE Trans. Geosc. Remote Sens. 2007, 45, 1835-1843. [CrossRef]

29. Wang, M. Remote sensing of the ocean contributions from ultraviolet to near-infrared using the shortwave infrared bands: Simulations. Appl. Opt. 2007, 46, 1535-1547. [CrossRef]

(C) 2020 by the authors. Licensee MDPI, Basel, Switzerland. This article is an open access article distributed under the terms and conditions of the Creative Commons Attribution (CC BY) license (http://creativecommons.org/licenses/by/4.0/). 